\title{
CONTRIBUIÇÕES DO TRABALHO PARA O BEM-ESTAR DO SUJEITO
}

\author{
Lucas Viero Furlan¹, Lilian Ester Winter², \\ Franciele Dutra ${ }^{3}$
}

\begin{abstract}
RESUMO: O ser humano é um ser social que necessita contato com outros sujeitos e pertencer a um grupo. Logo, o trabalho pode ser visto como promotor desses aspectos, possibilitando satisfação e bem-estar aos sujeitos. Assim sendo, esse artigo analisa a importância do trabalho para o bem-estar do sujeito, tendo em vista principalmente as relações com gestão e colegas de trabalho. Trata-se de uma pesquisa bibliográfica de caráter exploratório, onde se analisou a literatura científica brasileira dos últimos 10 anos. Os descritores utilizados foram "trabalho", "satisfação" e "bem-estar" na Biblioteca Virtual em Saúde - Psicologia Brasil, totalizando 10 resultados distribuídos nas bases de periódicos: Index Psicologia - Periódicos técnico-científicos (9 artigos) e Index Psicologia - Teses (1 tese). Percebe-se que o trabalho promove bem-estar desde que se invista no trabalhador com estratégias organizacionais que visem a promoção de saúde, realização pessoal e bem-estar através de afeto, cuidado e qualidade de vida.
\end{abstract}

Palavras-chave: Trabalho. Bem-estar. Qualidade de vida. Trabalhador. Sujeito.

Submissão: $14 / 05 / 2019$

Aceite: $26 / 07 / 2019$

DOI: $10.47591 / 2674-9203.2019 v 1 n 1 . a r t 1-1-9$

Este trabalho está licenciado com uma Licença Creative Commons Atribuição-NãoComercial 4.0 Internacional.

\footnotetext{
${ }^{1}$ E-mail: lucasvierofurlan@hotmail.com

${ }^{2}$ E-mail: lilian.winter@ fisma.com.br

${ }^{3}$ E-mail: francii_esteves@hotmail.com
} 
Compreende-se hoje o mundo moderno e globalizado como uma estrutura onde a produção é algo essencial na vida do ser humano, pois contribui com a manutenção da sociedade, por exemplo, através da atividade laboral. Isso evidenciase no posicionamento de Schaff (1993) e Lojkine (1990), que afirmam que o processo de globalização gerou e continua gerando alterações profundas nas formas de relações de trabalho e também nos modos de trocas comerciais, tanto em âmbito nacional quanto internacional. Na perspectiva desses autores, essas alterações corroboram para o aumento do crescimento financeiro que influencia a esfera política, portanto, aspectos da vida em sociedade, inclusive em âmbito individual, na satisfação que o ser humano apresenta, estando essa atrelada ao trabalhar e ao pertencer a um grupo com perspectivas semelhantes às suas.

Tendo em vista que o ser humano é um ser social, na visão de Capitão e Heloani (2007), no momento em que se observa um sujeito de forma isolada e acompanha o processo do seu desenvolvimento vital, se percebe que esse constituise a partir de um trajeto amplo que não se limita a fatores isolados. Nesse sentido, cabe considerar que aspectos pessoais estão em interação constante com um ambiente que contribui ativamente na formação das subjetividades. Inicialmente a família é o primeiro grupo do ambiente que atua como primeira fonte na constituição dos sujeitos, porém também não se limita a ela. Há outros contextos como escola, ensino superior, amizades, entre outros grupos variados em que este sujeito vai estar incluído e sentindo-se parte do coletivo. Muitas vezes a inserção no grupo de trabalho é um dos caminhos (BLEGUER, 1984) e é sobre isso que esse trabalho se propõe a discutir.

Diante disso, esse artigo tem como objetivo analisar a importância do trabalho para o bem-estar do sujeito, tendo em vista os aspectos atrelados à atividade laboral que promovem saúde e melhoria na qualidade de vida. Para isso, o estudo observa e discute principalmente as relações que se dão no ambiente de trabalho, como aquelas estabelecidas entre colegas de trabalho, gestores e entre ambos.

Estudos que permitam refletir acerca das influências que o trabalho exerce no bem-estar do sujeito são de importância elevada na contemporaneidade. Isso se evidencia na medida em que se observa que na atualidade a produção, por exemplo, na perspectiva capitalista, sobrepõe muitas vezes a necessidade humana de prezar pela sua saúde tanto física quanto mental. Nesse sentido, considera-se que os sujeitos possam se colocar em uma busca desenfreada em direção a objetivos muitas vezes fundamentados em aspectos positivos à lucratividade de uma organização, mas negativos no que se refere ao bem-estar e saúde subjetiva. Analisando a importância do trabalho para o bem-estar do sujeito, pode-se enxergar o objetivo dessa pesquisa como importante fator na compreensão dos aspectos atrelados ao trabalho que contribuem para um aumento dos resultados e eficiência do sujeito trabalhador. Assim sendo, essa investigação pretende contribuir na construção de estratégias de promoção de saúde e melhorarias na qualidade de vida e evolução da sociedade como um todo. 


\section{REVISÃO DE LITERATURA}

Estar inserido em um ambiente de trabalho que possibilite ao sujeito se sentir útil, integrado e pertencente a um grupo é investir na promoção de bem-estar e eficácia, entretanto a potencialização desses aspectos é um desafio na contemporaneidade para as organizações (FUNDAÇÃO NACIONAL DA QUALIDADE, 2013). Sendo assim, delineada por meio de uma breve revisão de literatura, discorre-se nessa seção sobre algumas temáticas visando possibilitar um maior entendimento acerca da problemática dessa pesquisa de forma a contextualizar o leitor.

\subsection{GESTÃO ORGANIZACIONAL E BEM-ESTAR DO TRABALHADOR}

Implantar programas de gestão em uma organização não é algo fácil de se fazer, visto que, segundo Gil (2016), considerar o "lado humano da qualidade" (p.286) exige atenção devido à complexidade e amplitude de variáveis envolvidas em cada ser subjetivo. De acordo com Patro (2013), os responsáveis pela gestão de pessoas geralmente enfrentam diversos desafios no processo de implantação desses modelos organizacionais de gestão de pessoas. Nesse sentido, a motivação do trabalhador é quem vai proporcionar à organização resultados qualitativamente positivos, mas isso implica na necessidade de um plano de gestão que considere as capacidades e potencial de cada trabalhador para que não se corra o risco de sobrecarregá-los com demandas, o que segundo Mc Dermott, Mikulak e Beauregard (1997), desencorajaria o trabalhador e comprometeria o seu bem-estar e motivação de estar engajado no processo e nos objetivos da organização a qual faz parte. Dessa forma, é perceptível a relevância de um plano gestacional bem elaborado para que assim tanto o trabalhador seja beneficiado quanto a instituição a qual faz parte.

De forma a complementar, Gil (2016) afirma que a motivação dos empregados não é suficiente para a organização alcançar resultados de qualidade. Segundo esse autor, a motivação é responsável pelo impulso à ação o que não implica a qualidade dessa ação. Sobre o fator qualitativo, Gil (2016) vai dizer que para que o trabalhador tenha condição de prezar pela qualidade, é necessário que a organização construa medidas estratégicas tendo em vista o melhoramento das condições de trabalho, destacando as recompensas e promoção de confiança e relações otimistas entre os trabalhadores, o que ocasionaria um aumento do bemestar do trabalhador provindo do próprio meio de trabalho.

\subsection{TRABALHO E PERTENCIMENTO AO GRUPO}

Conforme Bleguer (1984), o ser humano tem no trabalho dentro de uma organização interesses relacionados a necessidades de apoio, segurança, identidade e sensação de pertencimento grupal. Esse posicionamento permite a reflexão sobre o déficit de relações interpessoais dentro do ambiente de trabalho ser um fator contribuinte para a desmotivação e até mesmo a alienação do trabalhador que dessa forma é prejudicado no que se refere ao seu bem-estar, contribuindo negativamente para a qualidade dos serviços prestados por determinada organização. 
Nesse sentido, Gil (2016) aponta que a "cultura de qualidade" (p. 288-289) remete a ideia de que nas organizações os ideais, princípios adotados, valores e crenças influenciam a ação da instituição como um todo, ou seja, tanto positivamente quanto negativamente em relação aos seus objetivos particulares. Esse autor relata que as organizações que adotam esses valores geralmente possuem trabalhadores mais estimulados a prezarem pela qualidade sem se sentirem insatisfeitos ou descontentes com isso, pois identificam um fundamento por traz de suas ações, o que em última instância corrobora com uma sensação de bem-estar. Do mesmo modo, se o contrário vigorar, sendo, por exemplo, a gestão exercida de forma alienante, é provável que o trabalho prestado por todos os segmentos e subgrupos da organização sintam de forma direta ou indireta o "clima organizacional" como algo que deturpa a qualidade das relações e o bem-estar do trabalhador.

Na perspectiva pessimista de Capitão e Heloani (2007), a complexidade de fatores humanos envolvidos no ato de trabalhar e pertencer a uma instituição pode ser contribuinte para que o trabalho seja promotor de uma realidade sofrida e angustiante, entretanto, em sua visão otimista, defende também ser possível que o trabalho seja uma oportunidade de receber investimentos afetivos, cuidado, qualidade de vida e bem-estar. Ambas as perspectivas apresentadas por este autor são significantes e devem ser consideradas no processo de análise do funcionamento de uma organização.

\section{MÉTODO}

0 estudo foi realizado tendo em vista a metodologia de pesquisa bibliográfica exploratória que, segundo Gil (2002), objetiva familiarizar o pesquisador com o conhecimento já existente acerca da problemática que originou o objetivo do estudo. Além disso, adotou-se a noção de Prodanov (2013) no processo de escolha dos procedimentos técnicos para construção da pesquisa, onde ele defende que uma pesquisa bibliográfica pode ser constituída por documentos científicos tais como artigos, livros, revistas, dissertações e teses a serviço de uma maior abrangência de dados diversificados sobre a temática em questão.

Para coletar os dados, utilizou-se os descritores "trabalho", "satisfação" e "bem-estar" na Biblioteca Virtual em Saúde - Psicologia Brasil, sendo que foram alcançados, após a análise dos critérios de inclusão e exclusão, um total de 10 resultados distribuídos nas bases de periódicos: Index Psicologia - Periódicos técnico-científicos (9 artigos) e Index Psicologia - Teses (1 tese).

Como critérios de inclusão foram utilizados somente documentos científicos publicados em língua portuguesa, pois buscou-se analisar a literatura científica brasileira. Todas os dados selecionados foram publicados no intervalo entre o ano de 2008 até setembro de 2018, visando publicações contemporâneas. Entretanto, na seleção dos livros não foi seguida essa delimitação no ano de publicação, pois estes foram selecionados tendo como critério os autores relevantes que discorrem acerca da temática. Os tipos de documentos utilizados foram artigos, teses, dissertações e livros. Os dados não pertinentes foram descartados considerando os seguintes critérios de exclusão: teses, monografias e artigos 
incompletos, pagos e repetidos; após a leitura e análise na ordem de título, resumo e íntegra, aqueles que não apresentaram relação com o objetivo da pesquisa.

A ordem do processo de construção da pesquisa foi a seguinte: 1) escolha da temática; 2) formulação do problema de pesquisa; 3) procura das fontes de dados científicos; 4) fichamento do material obtido; 5) leitura e análise do material tendo em vista os critérios de inclusão e exclusão; 6) categorização do assunto; 7) redação do texto.

\section{ANÁLISE E DISCUSSÃO DOS RESULTADOS}

Em pesquisa realizada por Santos, Vizzotto e Gonçalves (2015), buscou-se analisar os fatores motivacionais de profissionais docentes de universidades brasileiras, percebeu-se que a forma como uma empresa é organizada influencia diretamente na motivação e desempenho dos trabalhadores. Segundo esses autores, quanto maior a dimensão afetiva do vínculo estabelecido entre os sujeitos que trabalham a favor da manutenção de uma organização, maior os laços relacionais e a satisfação em permanecer no lugar de trabalho, isso devido ao sentimento de bemestar promovido pelo contexto.

Corroborando com a visão de Santos, Vizzotto e Gonçalves (2015), em investigação acerca das consequências do suporte emocional fornecido através de informações a profissionais da saúde dentro do seu ambiente de trabalho, Gottardo e Ferreira (2015) concluíram que tal atitude é crucial na promoção de bem-estar a esses profissionais. Nos resultados obtidos por esses autores, a partir de uma amostra de 302 profissionais da saúde do Rio de Janeiro que realizaram avaliações psicológicas, foi constatado que quanto mais alta a percepção de amparo informacional de supervisores ou colegas de trabalho, maiores os índices de satisfação em forma de afetos dirigidos ao trabalho. Evidencia-se nesses casos uma tentativa de não corroborar com processos alienatórios dos trabalhadores, sendo que este compromete o bem-estar por atenuar a subjetividade dos sujeitos.

Investigando fatores atrelados ao bem-estar e qualidade de vida no trabalho, Silva e Ferreira (2013) destacaram três aspectos. São eles: satisfação no trabalho, comprometimento afetivo no âmbito organizacional e afetos positivos direcionados ao trabalho. Novamente o comprometimento afetivo aparece atrelado ao bem-estar do trabalhador. Em sua pesquisa, esses autores destacam como contribuintes para o desenvolvimento do bem-estar e qualidade de vida do trabalhador os benefícios extras e salários, as oportunidades de usar e desenvolver as próprias competências, segurança, comunicação entre empregados e supervisores e também relações interpessoais entre os colegas de serviço. Nesse sentido, Silva e Ferreira (2013), concluem que a oportunidade de usar e desenvolver as próprias capacidades foi o principal contribuinte para a manifestação dos três aspectos considerados representativos do bem-estar e qualidade de vida no trabalho.

Outro estudo realizado acerca do bem-estar no trabalho se deu por Goulart et al. (2012), onde se buscou apresentar a estruturação e propriedades psicométricas do Questionário de Bem-Estar no Trabalho, na sua versão brasileira. A importância deste estudo está atrelada à sua capacidade de medir de forma criteriosa aspectos psíquicos referentes ao bem-estar no trabalho. Sendo assim, essa 
ferramenta do profissional psicólogo contribui de forma significativa para análise de questões atreladas à satisfação no trabalho, sendo que os dados obtidos podem contribuir para a criação de estratégias de resolução de problemas diretamente dos trabalhadores e também, de forma indireta, da organização, sendo que a forma com que essa última funciona pode estar sendo a fonte dos conflitos.

Averiguando a influência de atividades no ambiente organizacional que visam a saúde do trabalhador, Couto e Paschoal (2012) recolheram dados de uma amostra de 130 trabalhadores de distintas organizações no Distrito Federal. Esses autores perceberam que quanto mais momentos de atividades como ginástica, relaxamento, musicalização e comemoração de aniversários, menor serão as manifestações de desprazer e mal-estar no trabalho. Em consonância, Sampaio (2012), por meio de uma revisão de literatura, pode identificar a predominância de conceitos e modelos teóricos de Qualidade de Vida no Trabalho utilizados no Brasil. 0 último autor mencionado constatou que a qualidade de vida no trabalho está vinculada a três fatores conceituais nucleares. São eles: a participação do empregado em decisões da gestão, bem-estar e humanismo, sendo este último uma síntese de motivação e satisfação.

A relação estabelecida entre trabalhador e organização de trabalho é influenciada pela vida particular do trabalhador, principalmente no que se refere às questões familiares. Pensando nisso, Teixeira e Nascimento (2011) realizaram entrevistas com o setor de recursos humanos de cinco empresas que adotaram medidas pró-família visando aumentar a produtividade e bem-estar dos colaboradores. Como resultado, constataram que apoio pessoal, celebrações de datas especiais, flexibilização de horários, medidas ocupacionais de tempo livre, atribuição de prêmios e subsídios financeiros foram contribuintes para melhorar o bem-estar dos colaboradores tendo em vista a conciliação do trabalho com a vida familiar.

No mesmo sentido, pensando o trabalhador como suscetível a sofrer influência do contexto familiar, Cia e Barhan (2008), compararam condições de trabalho, envolvimento familiar e bem-estar entre um grupo de trabalhadores do turno diurno e noturno. Os resultados destacaram que os trabalhadores do turno noturno aparentaram maior satisfação no que se refere a ter mais apoio dos colegas e supervisores, satisfação quanto ao salário, benefícios e poucas interrupções no expediente, entretanto menor satisfação devido ao turno de trabalho permitir contato reduzido com os filhos. Logo, observa-se que a vida pessoal do trabalhador é outro aspecto que deve ser levado em consideração quando o objetivo é a promoção e manutenção do seu bem-estar, visando também a manutenção do funcionamento organizacional.

Conflitos podem ser vistos tanto de forma construtiva quanto destrutiva. Um conflito motivado por divergências de ideias e posicionamentos diante de uma determinada questão podem dar lugar a uma nova visão. 0 mesmo ocorre no processo de formulação de uma tese, onde de um lado é apresentado uma tese e no outro uma antítese, ambas dando lugar a uma nova tese. Entretanto, conflitos podem arruinar uma organização quando seus fundamentos não são investigados com cautela. Nesse sentido, outro fator influente na promoção de bem-estar do trabalhador é o supervisor enquanto figura de poder, os conflitos entre os supervisores, entre subordinado e supervisor e também as divergências 
intergrupais (RESENDE, MARTINS e SIQUEIRA, 2010). No estudo referenciado, constata-se que o envolvimento no trabalho, comprometimento afetivo e principalmente satisfação no trabalho são geralmente prejudicados pelos próprios supervisores, principalmente quando há complicações na definição de tarefas ou abuso do poder, pois estas acabam obscurecendo a investigação dos fundamentos do conflito, inviabilizando sua resolução possivelmente por questões pessoais daqueles que seriam os principais encarregados de encontrar soluções.

Em pesquisa de campo com 2.438 funcionários de uma empresa, visando identificar a influência de variáveis demográficas do clima social e de formas de enfrentamento do estresse para o bem-estar no trabalho, foi observado que escolaridade e idade impactou consideravelmente, enquanto gênero não (ROCHA, 2009). Nessa mesma pesquisa, Rocha (2009), observou que quanto maior a autonomia dada aos trabalhadores, maior o bem-estar; quanto mais reconhecimento, maior a inovação e desempenho; quando o objetivo foi enfrentar o estresse dos funcionários, quanto maior foi o controle e manejo por parte dos gestores, melhores os resultados. Novamente o papel dos gestores, assim como na pesquisa de Resende, Martins e Siqueira (2010), é apontado como um dos mais importantes no processo de resolução de problemas, ou seja, na manutenção do bem-estar da organização como um todo.

\section{CONCLUSÕES}

Esse artigo, buscou compreender a importância do trabalho para o bemestar do sujeito, tendo em vista explanar os aspectos atrelados ao trabalho que promovem saúde, melhor qualidade de vida e bem-estar. Para isso, observou e propôs reflexões principalmente atreladas às relações no ambiente de trabalho que se estabelecem entre os diversos setores que compõem uma organização como aquelas entre gestores e outros funcionarios.

Constata-se que o trabalho, incluindo o seu contexto de relações interpessoais, é um importante contribuinte para o bem-estar do trabalhador. Isso se evidencia nos estudos que remetem a resultados onde o ambiente e condições de trabalho são considerados satisfatórios e até prazerosas desde que invistam na pessoa do trabalhador de forma para além do salário, ou seja, com estratégias organizacionais que visem a promoção de saúde, realização pessoal e bem-estar ao trabalhador. Como formas de promover tais coisas, percebe-se que o reconhecimento e apoio dos colegas e supervisores, autonomia no desenvolvimento de atividades incumbidas, celebração de datas especiais e outros fatores voltados ao desenvolvimento de relações interpessoais afetivas são aspectos que se destacam.

Entretanto, percebe-se que o trabalho, além de um propiciador de bemestar, também pode ser a causa de descontentamentos, estresse e mal-estar. Isso se mostrou principalmente atrelado às formas de gestão de pessoas adotadas pelas empresas que não valorizam o funcionário como um ser dotado de subjetividade e de uma vida fora do trabalho. Entretanto, tendo em vista o objetivo desta pesquisa, essa é uma problemática para pesquisas futuras, assim como a questão das implicações negativas da alienação dos trabalhadores no ambiente organizacional e seus impactos negativos aos objetivos da organização como um todo. 
Considera-se que os dados levantados e discutidos nessa pesquisa sejam de importância elevada na atualidade, pois, como os estudos científicos mostram, o resultado do trabalho está atrelado ao bem-estar do trabalhador não só dentro do trabalho como também para além disso, considerando sua vida pessoal, o que engloba as suas relações familiares, lazer e vínculos sociais. Assim sendo, permanecer em uma lógica de produção elevada sustentada por um modelo capitalista pode ser um entrave se aspectos subjetivos do trabalhador como motivação, bem-estar e objetivos de vida não forem levados em consideração. Além disso, é perceptível que a relevância de um plano gestacional de pessoas bem elaborado, tendo em vista os aspectos citados, é de grande valia para que tanto o trabalhador seja beneficiado quanto a instituição a qual ele faz parte.

\section{REFERÊNCIAS}

BLEGUER, J. Psico-Higiene e Psicologia institucional. Porto Alegre: Artes Médicas Sul, 1984.

CAPITÃO, C. G.; HELOANI, J. R. A identidade como grupo, o grupo como identidade. Aletheia, Canoas, n. 26, p. 50-61, dezembro de 2007. Disponível em:

<http://pepsic.bvsalud.org/scielo.php?script=sci_arttext\&pid=S1413-

03942007000200005\&lng=pt\&nrm=iso >. Acesso em 21 de setembro de 2018.

CIA, F.; BARHAM, E. J. Trabalho noturno e o novo papel paterno: uma interface difícil. Estud. psicol. (Campinas), Campinas, v. 25, n. 2, p. 211-221, junho de 2008. Disponível em:

<http://www.scielo.br/scielo.php?-

script=sci_arttext\&pid=S0103166X2008000200006\&lng=en\&nrm=iso $>$. Acesso em: 25 set. 2018.

COUTO, P. R; PASCHOAL, T. Relação entre ações de qualidade de vida no trabalho e bem-estar laboral. Psicol. Argum; 30(70): 585-593, julho-setembro, 2012. Disponível em:

https://periodicos.pucpr.br/index.php/psicologiaargumento/article/vi-ew/20563/19811. Acesso em: 24 set. 2018.

FUNDAÇÃO NACIONAL DA QUALIDADE. Critérios de excelência: avaliação e diagnóstico da gestão organizacional. 20ª ed. São Paulo: Fundação Nacional da Qualidade, 2013.

GIL, A. C. (1946). Como elaborar projetos de pesquisa. 4ª Edição. São Paulo: Atlas, 2002.

GIL, A. C. Gestão de pessoas: enfoque nos papéis estratégicos. 2ª edição. São Paulo: Atlas, 2016.

GOTTARDO, L. F. da S.; FERREIRA, M. C. Suporte social, avaliações autorreferentes e bem-estar de profissionais de saúde. Arq. bras. psicol., Rio de Janeiro, v. 67, n. 1, p. 146-160, 2015. Disponível em <http://pepsic.bvsalud.org/scielo.php?script=sci_arttext\&pid=S180952672015000100011\&lng= pt\&nrm=iso $>$. Acesso em: 23 set. 2018.

GOULART, P. M. et Al. Questionário de Bem-Estar no Trabalho: estrutura e propriedades psicométricas. Estud. psicol. (Campinas), Campinas, v. 29, supl. 1, p. 657-665, dezembro de 2012. Disponível em:

<http://www.scielo.br/scielo.php?script=sci_arttext\&pid=S0103166X2012000500002\&lng=en\& nrm=iso > . Acesso em: 24 set. 2018.

LOJKINE, Jean. A classe operária em mutações. Belo Horizonte, Oficina de Livros, 1990.

MCDERMOTT, R.; MIKULAK, R.; BEAUREGARD, M. C. Qualidade impulsionada pelos empregados. São Paulo: Makron Books, 1997.

PATRO, C. S. The role of human resource magement in implementation of TQM. International Journal of Computer Science and Management Research, v. 2, n. 6, junho de 2013. 
PRODANOV, C. C. Metodologia do trabalho científico: métodos e técnicas da pesquisa e do trabalho acadêmico. 2. ed. Novo Hamburgo: Feevale, 2013.

RESENTE, P. C. de; MARTINS, M. do C. F.; SIQUEIRA, M. M. M. Bem-estar no trabalho: influência das bases de poder do supervisor e dos tipos de conflito. Mudanças - Psicologia da Saúde, 18 (1-2), JanDez, 2010 (p.47-57). Disponível em:

https://www.metodista.br/revistas/revistasims/index.php/MUD/article/view/22-59/2415. Acesso em: 24 set. 2018.

ROCHA, S. F. Bem-estar no trabalho, clima social e estratégias de enfrentamento do estresse. 2009. p. 94. Tese (Mestrado em Psicologia). Universidade Católica de Brasília, Brasília, 2009. Disponível em: https://bdtd.ucb.br:8443/jspui/bitstream/1234-

56789/1915/1/Texto\%20completo\%20Fabio\%20Rocha\%20-\%202009.pdf. Acesso em: 25 de set. 2018.

SAMPAIO, J. dos R. Qualidade de vida no trabalho: perspectivas e desafios atuais. Rev. Psicol., Organ. Trab., Florianópolis, v. 12, n. 1, p. 121-136, abr. 2012. Disponível em:

$<$ http://pepsic.bvsalud.org/scielo.php?script=sci_art-

text\&pid=S198466572012000100011\&lng=pt\&nrm=iso $>$. Acesso em 24 set. 2018.

SANTOS, J. C. V. dos; VIZZOTTO, M. M.; GONÇALVES, G. Antecedentes do bem-estar no trabalho: o caso das universidades brasileiras. Mudanças; 19(19): 15-34, 2015. Disponível em: <http://pesquisa.bvsalud.org/portal/resource/pt/psi-68576>. Acesso em: 23 de setembro de 2018.

SCHAFF, A. A sociedade informática. São Paulo, Unesp-Brasiliense, 1993.

SILVA, C. A. da; FERREIRA, M. C. Dimensões e indicadores da qualidade de vida e do bem-estar no trabalho. Psic.: Teor. e Pesq., Brasília, v. 29, n. 3, p. 331-339, set. 2013. Disponível em: $<$ http://www.scielo.br/scielo.php?script=sci_arttext\&pid=S-

010237722013000300011\&lng=en\&nrm=iso >. Acesso em 23 de setembro de 2018. http://dx.doi.org/10.1590/S0102-37722013000300011.

TEIXEIRA, R.; NASCIMENTO, I. Conciliação trabalho-família: contribuições de medidas adotadas por organizações portuguesas. Rev. bras. orientac. prof, São Paulo, v. 12, n. 2, p. 215-226, dez. 2011. Disponível em: <http://pepsic.bvsalud.org/scielo.php?script=sci_arttext\&pid=S167933902011000200009\&lng= pt\&nrm=iso >. Acesso em 24 set. 2018. 